\title{
O processo de implantação de modelo de governança em uma cooperativa de crédito: um estudo de caso
}

The governance model implementation process in a credit cooperative: a case study

\section{Pedro Luís Büttenbender', Dirce Maria Schreiner", Ariosto Sparemberger"I', Bruno Nonnemacher Büttenbender ${ }^{\text {IV }}$}

\footnotetext{
' Universidade Regional do Noroeste do Estado do Rio Grande do Sul.plbutten@gmail.com " Universidade Regional do Noroeste do Estado do Rio Grande do Sul. ddirce.schreiner@gmail.com

III Universidade Regional do Noroeste do Estado do Rio Grande do Sul. ariosto@unijui.edu.br IV Universidade Regional do Noroeste do Estado do Rio Grande do Sul. brunonbuttenbender@gmail.com
}

\section{RESUMO}

Este estudo versa sobre gestão e governança corporativa e teve por objetivo diagnosticar as vantagens, desafios e aprimoramentos decorrentes da implantação de nova estrutura de governança na Cooperativa de Crédito - Cresol Santo Cristo. A pesquisa caracteriza-se como exploratória, descritiva e estudo de caso. As fontes foram secundárias, por meio de dados bibliográficos e documentais, e primárias, através de entrevistas com dirigentes, lideranças e especialistas em cooperativismo. Assim reconhece aportes da pesquisa participante e de observação direta. Os resultados revelam o aprimoramento das estruturas de gestão e governança do cooperativismo de crédito, com investimentos em capacitação de dirigentes, gestores, colaboradores e associados, a valorização dos princípios cooperativos, combinados com o desenvolvimento da gestão de negócios, a transparência, e sustentabilidade e a adequação a exigências regulamentadoras do mercado financeiro. $O$ estudo promove também o alinhamento de diretrizes pela Cooperativa Central Sicoper, ao passo em que desenvolve a performance cooperativa e competitiva, contribuindo com a intercooperação e qualifica o sistema cooperativo de crédito e a sua sustentabilidade.

Palavras-chave: governança corporativa, cooperativas de crédito solidário, gestão de cooperativas. 


\begin{abstract}
This study deals with management and corporate governance and aimed to diagnose the advantages, challenges and improvements resulting from the implementation of a new governance management structure at the Credit Cooperative - Cresol Santo Cristo. The research is characterized as an exploratory, descriptive and field case study. The sources were secondary, based on bibliographic and documentar data, and primary, through interviews with leaders, leaders and experts in cooperativism. It recognizes contributions from participant research and direct observation. The results reveal the improvement of credit cooperative governance structures, with investments in training of managers, managers, employees and associates, the valuation of cooperative principles, combined with the improvement of business management, transparency, and sustainability. compliance with financial market regulatory requirements It also promotes alignment of guidelines by Cooperative Central Sicoper, develops cooperative and competitive performance, contributes to intercooperation and qualifies the cooperative credit system and its sustainability.
\end{abstract}

Keywords: corporate governance, solidarity credit cooperatives, management of cooperatives.

\title{
1. INTRODUÇÃO
}

As cooperativas apresentam uma estrutura diferente de outras empresas, por possuir uma arquitetura organizacional diferente, em especial, na distribuição do poder e dos próprios resultados, o que pode, a partir de uma gestão eficiente oferecer vantagens, quando comparadas a empresas de outros setores e atividades. Desta forma, o modelo de coordenação do negócio e de suas atividades é determinante para o crescimento e o desenvolvimento da cooperativa. Entretanto, por estarem inseridos em um ambiente hipercompetitivo em decorrência principalmente da globalização dos mercados, os processos de gestão e governança precisam estar adequadas as novas regras e normas do próprio sistema cooperativo estabelecidos de forma a propiciar maior eficiência e eficácia ao cooperativismo.

Nesta direção, Siqueira e Bialoskorski (2014), entendem a governança como uma forma de coordenação em que a organização cooperativa minimiza os custos de transação em determinado ambiente institucional. Portanto, estudos que possam analisar a forma com que as cooperativas estão lidando e trabalhando são importantes à medida que oferecem ao cooperativismo e ao leitor, experiências inovadoras no tema da gestão e da governança. 
Assim sendo, este trabalho consiste num estudo sobre os desafios da implantação de uma nova estrutura de governança que implica em mudanças nas ações da diretoria executiva no sistema de cooperativas de crédito, seus percalços e êxitos, na busca por analisar a importância e os favorecimentos desta medida, a consistência de um sistema de governança cooperativa e o desafio da necessidade de haver instrumentos cada vez mais eficazes e eficientes no controle gerencial da cooperativa de crédito.

Demonstra-se neste trabalho, que o cooperativismo de crédito não pode prescindir dos fundamentos teóricos da governança corporativa, que influenciam diretamente no conselho de administração e diretoria executiva e no papel de cada um deles.

Este estudo apresenta relevância por diversas características, e reconhece que vários estudos já foram realizados sobre governança corporativa. Por exemplo, destacam-se Carvalho (2002) e Andrade e Rossetti (2007). Sobre governança corporativa em cooperativas, as produções de Schardong (2004), IBGC (2009), Ventura (2009), Siqueira e Bialoskorski (2014), Meinen e Port (2014), Büttenbender (2017), Büttenbender e Outros (2017 e 2016). Em específico, a abordagem do tema em cooperativismo de crédito, destaca-se também os aportes de Magri (2010), Pies (2017), Büttenbender e Magri (2018), onde exploram o tema da governança corporativa em cooperativas de crédito de interação solidária.

A pesquisa caracteriza-se como exploratória, descritiva e estudo de caso (YIN, 2010). Foram utilizados dados secundários, através de bibliografias, documentos, Atas e registros da cooperativa. As fontes de dados primários sustentam-se na realização de entrevistas com dirigentes da cooperativa e da cooperativa central e entrevistas com estudiosos do cooperativismo, da gestão e da governança corporativa. O estudo também reconhece a qualificação da pesquisa participante e da observação direta, 
pois os autores são membros da organização estudada. A sistematização e análise de dados foram orientadas pelos objetivos do estudo.

O presente documento estrutura-se em cinco seções, a primeira proporciona uma introdução e contextualização do estudo, a segunda os fundamentos conceituais e os antecedentes na literatura. A terceira seção apresenta os procedimentos metodológicos, a quarta explora a descrição e análise do estudo propriamente dito e a quinta com as conclusões e bibliografias.

\section{ANTECEDENTES NA LITERATURA}

Os autores referenciados para reforçar os argumentos evidenciam o uso do controle gerencial para identificar e medir o resultado produzido pelos diferentes setores da cooperativa. Com esta perspectiva, considera-se necessária a contextualização das abordagens acerca da gestão de cooperativas observada através da ótica da governança - corporativa e cooperativa - para que assim sejam compreendidos os diferentes desafios constantes no meio em questão.

\subsection{Gestão de cooperativas}

Em sua essência, uma cooperativa tem objetivos sociais e econômicos, integrando pessoas na busca de uma vida melhor. Para que esta missão seja de fato cumprida, é necessário dar-Ihe um caráter profissional desde seu planejamento. É de grande importância planejar, criar legalmente, organizar, dirigir e controlar uma organização cooperativa. Com a forte concorrência interna e externa, torna-se fundamental administrar de forma eficiente e eficaz esse tipo de organização para a consecução de seus objetivos (BÜTTENBENDER, 2011).

Na Lei 5.764 de 1971 (BRASIL, 2018), conhecida Lei do Cooperativismo, determina o artigo 47 que a sociedade será administrada por uma diretoria ou 
Conselho de Administração, composto exclusivamente de associados eleitos pela Assembleia Geral, com mandato nunca superior a 4 (quatro) anos, sendo obrigatória a renovação de no mínimo 1/3 (um/terço) do Conselho de Administração. No entanto, ainda na mesma lei, no artigo 48, prevê que, os órgãos de administração podem contratar gerentes técnicos ou comerciais, que não pertençam ao quadro de associados, fixando-lhes atribuições e salários.

O Código de Boas Práticas de Governança do IBGC (2009) retoma e reforça a natureza jurídica das empresas do terceiro setor, especificamente o conceito para cooperativas: "Sociedades de pessoas, constituídas para prestar serviços aos associados, cuja distribuição de resultado está vinculada as operações efetuadas pelo sócio com a sociedade e desvinculada da participação no capital e cujos direitos políticos estão vinculados às pessoas e desvinculados da participação de capital." A participação dos associados na organização, tanto utilizando seus produtos, como na construção e gestão da cooperativa está acima do capital financeiro investido.

Conforme reforça Büttenbender (2010) o conceito de gestão democrática e eficiente passa também por um projeto coletivo que tem como meta aumentar a competitividade das empresas assistidas, o que requer uma abordagem interdisciplinar, principalmente com o advento das tecnologias de informação e comunicação, fazendo da cooperativa um espaço de relevância, como instrumento de difusão e informação do conhecimento. Destaca ainda que desde 1844, quando foi fundada a primeira cooperativa do mundo, na Inglaterra, a gestão democrática, está presente, compreendendo o segundo princípio do cooperativismo e continua atual.

O cumprimento da missão da organização se dará, uma vez que os princípios sejam observados e seguidos integralmente. Para Siqueira e Bialoskorski (2014), o desafio das estruturas cooperativas modernas é manter seu papel de sistema produtivo centrado no homem e, ao mesmo tempo, desenvolver uma organização 
capaz de competir com empresas de outras naturezas com orientação para o mercado.

Por fim, é preciso ter em mente que não são as pessoas a razão do sucesso ou fracasso das organizações cooperativas, mas sim a capacidade de gestão existente e capacidade de estas trabalharem juntas para construir algo maior que suas limitações e sonhos individuais.

Para Schardong (2003), os valores éticos e princípios de gestão são os fatores que norteiam o destino das cooperativas de crédito. Uma boa governança tende assegurar que as decisões estejam alinhadas com os interesses dos cooperados, ampliando a credibilidade deles em relação as informações fornecidas pela cooperativa.

A implementação das boas práticas de governança corporativa possibilita uma gestão mais profissionalizada e transparente, uma vez que não se concentra apenas em disciplinar as relações entre as diversas áreas de uma organização ou com partes externas, mas, também, converge os interesses de todas as partes relacionadas, buscando maximizar a criação de valor na empresa.

Estabelece-se assim entre os dois agentes, os acionistas e os gestores, uma relação de agência, fundamentada na contratação de decisões que maximizem o valor do empreendimento, a riqueza dos acionistas e o retorno de seus investimentos. Andrade e Rossetti (2007) reiteram que a teoria já consagrada da governança corporativa os denomina de conflitos de agência, associando-os a dois axiomas fundamentais: a inexistência do contrato completo e a inexistência do agente perfeito. 


\subsection{Governança cooperativa e a governança corporativa}

Para o BACEN (2015), governança cooperativa compreende o conjunto de mecanismos e controles, interno e externo, que permite aos cooperados definir e assegurar a execução dos objetivos da cooperativa, garantindo sua continuidade e os princípios cooperativistas. Ou seja, tem a finalidade de combater as relações desiguais de trocas e de financiamento nas atividades rurais e urbanas e, principalmente, consolidar a concessão de crédito mais compatível com a realidade dos trabalhadores dessas áreas.

Segundo conceito do IBGC (Instituto Brasileiro de Governança Cooperativa), Governança Corporativa é o sistema pelo qual as organizações são dirigidas, monitoradas e incentivadas, envolvendo as práticas e os relacionamentos entre proprietários, conselho de administração, diretoria e órgãos de controle. As boas práticas de Governança Corporativa convertem princípios em recomendações objetivas, alinhando interesses com a finalidade de preservar e otimizar o valor da organização, facilitando seu acesso ao capital e contribuindo para a sua longevidade.

A governança é o conjunto de processos, políticas, leis e regulamentos que regem a maneira como uma cooperativa é dirigida e administrada. Se for eficiente a governança vai assegurar a solidez e a eficiência econômica da cooperativa; resguardar a obtenção dos devidos resultados desta e assegurar a transparência ao processo de gestão. Para Ventura (2008), a construção de diretrizes de boas práticas de governança para qualquer setor ou grupo de organizações deve se pautar em suas características próprias, nas forças e fraquezas nas relações entre proprietários, gestores e grupos de interesses (stakeholders). Não devem constituir simples adaptação de diretrizes elaboradas para outros setores, ou ser extraídas de códigos internacionais de boas práticas. Assim a definição de diretrizes para as cooperativas de crédito brasileiras deve considerar, as relações entre cooperados, os gestores, a comunidade em que se situam, as demais instituições do sistema financeiro, o Banco 
Central na qualidade de regulador e fiscalizador, as demais instituições do segmento cooperativista, como a confederação, e as organizações que apoiam as cooperativas, tais como empresas, associações ou órgão público.

Para o segmento cooperativista de crédito (VENTURA, 2008), as diretrizes de boa governança devem contribuir para: 1) Equilibrar os sistemas internos e externos de controle, de forma que se minimizem os custos e melhore sua efetividade; 2) Reduzir o custo da decisão coletiva e melhorar o processo decisório dos proprietários; 3) Assegurar gestão eficiente e monitorar a atuação dos gestores; 4) Promover alinhamento de interesse dos gestores e dos técnicos com as prioridades da cooperativa; e 5) Preservar a equidade no tratamento dos interesses dos diversos associados.

Ainda no que tange aos princípios de governança, destacam-se os princípios básicos que segundo o IBGC (2009), dentro do Código das Melhores Práticas de Governança Corporativa, são: 1) Transparência (disclosure); 2) Equidade; 3) Prestação de Contas (accountability); e 4) Responsabilidade Corporativa. Complementarmente, no que se refere a governança corporativa em cooperativas, o BACEN (2015) define que a solidez e a eficiência do sistema financeiro, de forma geral, e do segmento de cooperativas de crédito, particularmente, requer uma boa governança corporativa. Nesse sentido, corroboram Ventura (2009) e Soares e Melo Sobrinho (2008), que um adequado sistema de governança corporativa pode viabilizar o crescimento sustentado do segmento de cooperativas de crédito no Brasil, contribuindo com a sua solidez, e aprimorando os mecanismos de monitoramento pelo Banco Central.

\subsection{Desafios da governança corporativa em cooperativas}

Os desafios da governança em cooperativas são explorados por distintos autores, destacando-se Meinen e Port (2014), quando externam a preocupação com a governança nas instituições financeiras cooperativas, considerando o plano da 
composição e do funcionamento dos órgãos de administração. Apesar da abordagem recente, enfatizam os autores, que há convergência na priorização de que as cooperativas, na medida que se expandem no número de associados e aumentam no volume de negócios, tornam-se mais complexas, requerendo estruturas de gestão mais qualificadas e atuantes. Por exemplo, de um lado, o conselho de administração mais protagonista, liderando assuntos da ordem estratégica no interesse dos associados, e, por outro lado, dirigentes executivos com maior competência de gestão, em condições de conduzir a operação.

Na evolução recente, o modelo de gestão mais característico, é o que expressa o comando da Direção Eleita, que além das funções estratégico-associativas, acumulam também a gestão técnico-operacional, sem, no entanto, terem as competências técnico-gerenciais requeridas para estas funções (MEINEN e PORT, 2014).

Nesta dimensão, destaca Büttenbender (2017), referindo-se a governança corporativa em cooperativas, a importância da qualificação das estruturas, contemplando a valorização estratégico-associativa da natureza das Cooperativas, e o desenvolvimento das competências de gestão e governança das estruturas técnicogerenciais das cooperativas.

No que se refere à gestão e à governança corporativa em cooperativas de crédito, Meinen (2018) acompanha Ventura (2009) e Soares e Melo Sobrinho (2008), reconhecendo que o Brasil possui um abrangente e sofisticado modelo normativo dedicado ao cooperativismo, considerando as cooperativas de crédito um instrumento fundamental para a inclusão e educação financeira, o desenvolvimento socioeconômico do país e a ampliação da competividade no mercado dos serviços financeiros. 
O processo de contínua evolução e aprimoramento é destacado por Pies (2017) quando sustenta a tese de três pilares de mudanças que afetam as cooperativas de crédito e suas práticas de governança. Sustenta o autor que o primeiro pilar é o do marco regulatório do cooperativismo de crédito, expedido pelo Estado brasileiro, que estabelece regras, por exemplo, para a transparência, prestação de contas e práticas de governança. Segundo o pilar normativo, pode ser observado na aderência, por parte das cooperativas de crédito, ao planejamento estratégico e as práticas de gestão. E, terceiro o pilar cultural-cognitivo, da busca constante do reconhecimento por parte da população quanto da importância das cooperativas de crédito para o desenvolvimento das comunidades.

\section{PROCEDIMENTOS METODOLÓGICOS}

O estudo trata-se de estudo de caso (YIN, 2010), de natureza exploratória, de abordagem qualitativa e de campo, quanto aos fins, se caracteriza como descritivo e analítico e quanto aos meios se caracteriza como um estudo de fonte primárias e outras secundárias. A natureza exploratória para o presente estudo por se tratar de uma área do conhecimento com poucas teorias (COLLIS; HUSSEY, 2005), permitindose o aprimoramento de ideias, de modo que venha a possibilitar a consideração de múltiplas dimensões do fenômeno estudado (GIL, 2002). A pesquisa também se caracteriza pela pesquisa participante e de observação direta (ZAMBERLAN, 2014).

Foram utilizadas fontes secundárias, como bibliografias, documentos, Atas e registros da cooperativa. Foram também realizadas visitas de campo, a Cooperativa Central Sicoper, ao Sistema Viacred-Cecred e a outras cooperativas, com o acesso a estatutos, políticas, manuais, resoluções e regimentos, disponíveis impressos e em meio digital As fontes de dados primários sustentam-se na realização de entrevistas com dirigentes da cooperativa e da cooperativa central e entrevistas com estudiosos do cooperativismo, gestão e governança corporativa. O estudo também reconhece a qualificação da pesquisa participante e da observação direta, pois autores são 
membros da organização estudada. A sistematização e análise de dados foram orientadas pelos objetivos do estudo.

As fontes primárias sustentam-se em entrevistas com líderes cooperativos e corporativos. Para as entrevistas foi utilizado um roteiro com questionário semiestruturado. As entrevistas, para fins da pesquisa, foram gravadas e transcritas. Foram realizadas entrevista com três conselheiros administrativos da Cresol Santo Cristo, o diretor executivo do sistema Cresol Sicoper, o diretor presidente da confederação Cresol; o Diretor executivo do sistema de cooperativas AILOS (anteriormente denominado CECRED).

Quanto à sistematização e a análise orientada pelos objetivos, com análise de conteúdo e de discurso, os dados foram organizados de acordo com os objetivos do trabalho, uma vez descritos, foi feita a análise a luz dos objetivos do estudo, visando identificar além de sua caracterização, a análise de aspectos positivos e desafios, bem como, ao final as respectivas proposições. A sistematização foi elaborada conforme os passos já descritos, contemplando a caracterização da Cresol Santo Cristo e do Sistema Cresol, mapeamento da estrutura de gestão e governança, desafios à governança corporativa em processo de implantação na Cresol e proposições.

\section{RESULTADOS}

A presente seção contempla a descrição do histórico do Sistema Cresol, os referenciais estratégicos da Cooperativa Cresol Sicoper, a Cooperativa Cresol Santo Cristo, Competências do organograma da Cooperativa e o processo de implantação da nova estrutura de gestão e governança na Cresol Santo Cristo. 


\subsection{Histórico do sistema Cresol}

O sistema Cresol é constituído de cooperativas de crédito rural com Interação Solidária. As primeiras cooperativas do Sistema Cresol foram constituídas em 1995. Ainda em 1996 foi criada uma Base de Serviços, em Francisco Beltrão - Paraná, a qual transformou-se posteriormente na primeira Central Cresol, denominada Central Cresol Baser. Devido ao forte incremento no número de cooperativas de crédito e a expansão da atuação constituiu-se, em $1^{\circ}$ de novembro de 2004 , a segunda central de crédito denominada Cresol Central SC/RS, localizada em Chapecó - Santa Catarina. A trajetória de sucesso da Cresol demonstra que a criação de novas centrais é um fator importante para o crescimento e pulverização do crédito qualificado.

Em 2014, dez anos depois, a terceira central foi constituída para ampliar o acesso, o volume de negócios, a eficiência dos serviços prestados, o número de associados e fortalecer ainda mais a marca Cresol. A nova central, denominada Central Cresol Sicoper, foi constituída no dia 27 de junho de 2014 e está sediada em Passo Fundo, no Rio Grande do Sul, contando também com uma sede administrativa localizada em Chapecó - Santa Catarina.

No princípio de sua história, o Sistema Cresol era um grupo de cooperativas formadas exclusivamente por agricultores familiares ou que provinham dela. Estes eram os cooperados e também gestores da organização financeira. Constituem um público de baixa renda que figurou historicamente como excluído das políticas governamentais de crédito rural e do circuito financeiro tradicional. Em sua área de atuação, portanto, essas cooperativas alcançam uma capilaridade importante, estendendo os serviços financeiros a essa parcela do mercado pouco visada por outras organizações do mesmo setor.

O surgimento da Cresol se deu por força da união de diversas entidades sindicais, pastorais e outros movimentos sociais. Foi por esta união de esforços e 
interesses comuns que foi concebida a Cresol, constituindo-se como uma cooperativa autogestionária que viabiliza o acesso ao sistema de micro finanças para fomentar a produção, principalmente àqueles que viviam excluídos do sistema financeiro. Além de ampliar a abrangência e o papel dos fundos, as cooperativas significaram um instrumento de gestão com uma grande capacidade de intervenção na economia e reconhecimento como instrumento financeiro dos agricultores familiares.

Com o passar dos anos, ainda recentemente contou-se com a possibilidade de trabalhar com o público urbano, conferida por diversos líderes do sistema, representava uma oportunidade de crescimento do sistema Cresol. Argumenta-se que a estrutura e os recursos disponíveis no sistema serão melhor aproveitados à medida que existir um público mais amplo para realizar negócios. Evidentemente o fato de atender especialmente o público jurídico, exige certa cautela e preparação das cooperativas para operar nesse contexto, porque as operações com esse segmento poderiam levar a uma concentração de carteira e poderiam elevar os riscos de inadimplência.

Com a implantação do atendimento ao público urbano e a expansão dos produtos e serviços oferecidos, aliados a uma boa gestão, o sistema Cresol cresceu e cresce de uma forma espetacular. Conforme sustentado por Magri (2018) o Sistema Cresol possui o seu formato organizativo e a sua vocação de atuar em prol da agricultura familiar, sempre articulado com outras forças vivas da sociedade, fazem com que o sistema cresça de forma significativa e comece a alcançar voos mais distantes. Este crescimento é o reflexo de diversas ações da Cresol que inspiram confiança no cooperado, fortalecendo cada vez mais esta cooperativa. 


\subsection{Referenciais estratégicos da Cooperativa Central Cresol Sicoper}

Orientada pelos preceitos da gestão estratégica, a Cresol possui bem definida a sua missão, visão e valores para direcionar suas principais ações. Como estas foram decididas no início de sua trajetória, elas partem do princípio de uma cooperativa fomentadora da agricultura familiar. A Missão da Cresol Sicoper é fomentar a cooperação entre associados, especialmente agricultores familiares e cooperativas, por meio do crédito orientado e da educação financeira construindo novos saberes, visando o desenvolvimento regional de forma sustentável e solidária. Por esta missão percebe-se uma preocupação não somente em alcançar credito para o financiamento de seus anseios, como também, um acompanhamento de suas propriedades orientando-os para um futuro promissor da propriedade.

A visão da Cresol Sicoper éser referência das cooperativas de crédito solidário do Brasil atuando em prol da agricultura familiar. Esta visão é ousada, porém encaminhando para de fato ser a cooperativa referência da agricultura familiar. Os Valores da Cresol são: Democracia, Transparência e confiança, Cooperação e solidariedade, Ética e profissionalismo, Articulação com os movimentos populares, Governança pelos agricultores familiares e Sustentabilidade institucional.

Afirmam nesta direção Magri e Pommerening (2018) que para a cooperativa que prima pela ética, sua missão, visão e valores não são meros jogos de palavras dispostos e emoldurados de parede, mas uma filosofia de vida a todos os que por eles são enlaçados. Neste sentido o Sistema Cresol Sicoper preza em sustentar, cultivar e preservar a missão, visão e os valores da cooperativa, por ser primordial para que o sentimento de cooperação esteja presente no dia a dia de seu quadro social. 


\subsection{Cresol Santo Cristo}

A Cresol Santo Cristo foi constituída em Assembleia Geral no dia 12.06.2003 por 31 associados, todos agricultores familiares. A Cresol é uma instituição financeira de natureza cooperativa, com responsabilidade limitada, sem fins lucrativos, regida pela legislação cooperativista, do Sistema Financeiro Nacional e pelo Código Civil, bem como pela regulamentação baixada pela autoridade normativa, pelo Estatuto Social e pelas normas internas. Como princípio básico, a administração feita por agricultores familiares, e seus colaboradores contratados também não provinham do sistema financeiro. Isto acarretou numa administração e num sistema operacional bastante amador, o que trouxe algumas dificuldades no início de sua trajetória.

Seu primeiro espaço de atendimento foi inaugurado no dia 24 de janeiro de 2004, numa sala de $48 \mathrm{~m}^{2}$, com pouca tecnologia. Foi um período de busca de novos associados, reuniões de prospecção de negócios. Assíduas negociações com o Banco do Brasil, BRDE e BNDES em busca de recursos para repassar aos associados pelo Programa Nacional de Fortalecimento da Agricultura Familiar- PRONAF, que é um programa do Governo Federal criado em 1995, com o intuito de atender de forma diferenciada os mini e pequenos produtores rurais que desenvolvem suas atividades mediante emprego direto de sua força de trabalho e de sua família.

Atendendo ao conjunto de relações do Sistema Cresol com outras instituições financeiras públicas, destacando Banco do Brasil, Caixa Econômica Federal, BNDES, BRDE e outros, a Cresol Santo Cristo ampliam a sua atuação no mercado local e regional e promove investimentos na ampliação da sua estrutura de atendimento. Em 2009 inaugura sua sede própria ampliando número de associados, de funcionários e de estrutura, expandindo e inaugurando em poucos anos, diversas unidades de atendimento em vários municípios da nossa região. 
Em 2019 a Cresol Santo Cristo conta com mais de 14.700 associados. Estruturalmente, além da sede que fica na cidade de Santo Cristo, possui mais 8 unidades de atendimento na nossa região, sendo nos municípios de Tuparendi, nesta possuindo duas unidades de atendimento, Candido Godoi, Santa Rosa, Três de Maio, Tucunduva, Campina das Missões e Porto Lucena. Possui um quadro de 67 colaboradores e dois Conselheiros Administrativos liberados. Além disto, um projeto e um plano de viabilidade para a expansão para o Vale do Taquari, ou seja, para os municípios de Teutônia e Salvador do Sul. Para 2020, existe a previsão de expansão para outros dois municípios da Serra Gaúcha. A logística de acompanhamento será mais dificultosa em função da distância, o que remete a se preocupar na contratação de extrema confiança e de nossa relação.

A Cresol destaca-se pelo atendimento humanizado e por excelência aos seus associados. Este diferencial da Cresol, beneficia especialmente ao público acima de 45 anos de idade, uma vez que destes muitos possuem dificuldades de se adequar a era digital. Cultivar um relacionamento transparente com os clientes sempre foi considerado de grande importância pela direção da Cresol. A finalidade é acolher seus associados com um atendimento personalizado, com empatia e simplicidade, deixando o cooperado à vontade na cooperativa. Com a variedade de produtos e serviços disponíveis no mercado, o bom atendimento torna-se uma virtude para quem quer fazer a diferença.

Sabe-se que um cliente satisfeito divulga de forma gratuita a experiência positiva que vivenciou na cooperativa para as demais pessoas, sendo este um marketing positivo e provedor do sucesso da cooperativa. Portanto, conquistar a fidelidade aumenta a probabilidade do cooperado divulgar de forma positiva a marca. Os associados tendem a se sentirem próximos daqueles que se dirigem com atendimento personalizado e trabalham ativamente para bem atender. Essa conexão gera confiança e mantem as pessoas não apenas satisfeitas, mas impressionadas positivamente. 
Pode-se destacar que o desenvolvimento do trabalho social, a inserção comunitária, a promoção do cooperativismo e o relacionamento humanizado no atendimento aos associados são percebidos enquanto elementos que contribuem no reconhecimento do Sistema Cresol na sociedade. Estas relações fomentam o relacionamento com o associado e a identidade cooperativista como principais diferenciais do cooperativismo, incentivando a busca constante a esta cooperativa pelos cooperados e futuros associados.

Outro fator determinante que eleva bastante o conceito da Cresol junto aos cooperados é a dimensão da solidariedade de alguma forma, associada ao trabalho social desenvolvido pelas cooperativas, expressada nas relações de ajuda para melhorar as condições de vida dos associados. Esta é uma forma de alinhar propósitos e diferenciais cooperativos para o fortalecimento da classe menos favorecida da sociedade.

\subsection{Competências do organograma da cooperativa}

As cooperativas estatutariamente são regidas pela Assembleia Geral, Conselho Fiscal e Conselho Administrativo, constituídos legalmente e aprovados pelo Banco Central do Brasil. Possuem um papel primordial e de suma importância, sendo os esteios e os eixos que conduzem o futuro e definem os rumos a serem seguidos pela cooperativa. Cada um com seu poder distinto. No organograma da estrutura Organizacional da Cresol Santo Cristo destaca-se a Assembleia Geral como o órgão máximo, seguida pelo Conselho Administrativo e o Conselho Fiscal. Para gerir a execução das diretrizes e operacionalização da cooperativa consta a Diretoria, com Conselheiro presidente e Vice-Presidente. Nos estatutos sociais estão detalhadas as atribuições de cada um dos órgãos de gestão superior.

Aos gestores contratados e demais funcionários colaboradores cabem colocar em ação as estratégias definidas pelo conselho administrativo e diretoria executiva, 
atendendo de forma direta a todos os associados e demais demandas da Cooperativa.

\subsection{A nova estrutura de gestão e governança na Cresol Santo Cristo}

As cooperativas de crédito, na medida em que crescem no número de associados, no volume de negócios e na complexidade operacional, requerem conselho de administração cada vez mais atuante e eficaz, liderando assuntos de ordem estratégica no interesse dos associados e clientes. Como isto, por vezes, existe a necessidade dos conselheiros administrativos, a importância de eleger diretores executivos cada vez mais capacitados tecnicamente, em condições de conduzir e executar as demandas definidas pelo conselho administrativo. As mudanças exigidas podem ser por força interna ou externa. Interna é a necessidade percebida no dia a dia das ações da cooperativa. Força externa são as normas estipuladas pelos órgãos reguladores, garantindo uma melhor gestão quando os indicadores financeiros alcançarem determinados limites.

A Lei Complementar n 130/2009 (BRASIL, 2019), que trata dos mecanismos de governança, estabelece, no artigo $5^{\circ}$, que as cooperativas de crédito com conselho de administração podem criar diretoria executiva a ele subordinada, na qualidade de órgão estatutário composto por pessoas físicas associadas ou não, indicadas por aquele conselho. A Governança corporativa era facultada através da Resolução do BACEN n 4.434, de 5 de agosto de 2015 (BACEN, 2018). E a Lei Complementar $n^{\circ}$ 130/2009 (BRASIL 2019) definiu como estrutura obrigatória. As cooperativas de crédito com ativos totais superiores a $\mathrm{R} \$ 50$ milhões deveriam então promover a segregação das funções classificadas como plenas e clássicas.

A Cresol Santo Cristo, afetada pelos indicadores financeiros estipulados e normatizados pelo Banco Central do Brasil, decidiu em Assembleia Geral Extraordinária, ocorrida no dia 24 de fevereiro de 2018, pela reforma Estatutária 
prevendo a implantação da Diretoria Executiva, conforme estimava a resolução 4434 do BACEN. Já na data seguinte de 26 de fevereiro, o Conselho Administrativo definiu os nomes a ocuparem os cargos na Diretoria Executiva e a Ata foi enviada junto com a documentação da (AGO) Assembleia Geral Ordinária e (AGE) Assembleia Geral Extraordinária para apreciação e aprovação do Banco Central.

No dia 03 de maio, a Cresol Santo Cristo recebeu a informação da aprovação, que foi formalizada em ofício datado em 12 de abril de 2018 da plena aprovação pelo Banco Central do Brasil. Já no dia 04 de maio de 2018, o Conselho Administrativo, prontamente reuniu-se para dar a posse aos membros das Diretorias Executiva, Administrativa e Comercial.

Enquanto a resolução n. 3041/2002 estabelece as condições para o exercício de cargos em órgãos estatutários de instituições financeiras e demais instituições autorizadas a funcionar pelo Banco Central do Brasil, a lei n. 130/2009 define as cooperativas como Instituições financeiras. Com isso, a capacitação técnica dos conselheiros com função executiva é fator incondicional, deixa de ser somente importante e passa a ser necessária. As atribuições e competências de cada um dos órgãos superiores de gestão e governança da cooperativa estão descritas e detalhadas no Estatuto Social da Cresol Santo Cristo. Destaca-se a importância de considerar o detalhamento da percepção de lideranças e sujeitos envolvidos nos processos de implantação da nova estrutura de gestão e governança na Cresol Santo Cristo.

Para Magri (2018) o sistema de cooperativismo necessita aperfeiçoar, em muito, os mecanismos de governança. Se não, teremos como resultado estruturas de poder onde a preocupação com a participação, a eficiência operacional e a rentabilidade dos cooperados serão secundarias. As mudanças de gestão sempre são e serão um grande desafio. Ainda mais quando envolve conselheiros administrativos antigos, sem muita percepção de gestão qualificada. Sempre existirá uma barreira a 
ser rompida. Argumenta Oliveira (2003) que o modelo de gestão pode provocar mudanças nas cooperativas e deve ser considerado um processo continuo. Isso porque, com base nas mudanças efetuadas, novos problemas devem surgir, o que exigirá novas soluções, as quais podem necessitar de novas abordagens de modelos de gestão. Sabe-se que existe uma dificuldade de aceitação e implantação do novo numa cultura conservadora, onde a situação atual representa uma zona de conforto.

Os processos de inovação, para Mota (1994) traduzem um conceito positivo e resultam na ideia de que algo de melhor está por acontecer. Ajuda dessa forma a criar esperança de dias melhores, a incentivar sonhos e a aceitar mais facilmente as dificuldades presentes. A resistência na implantação de inovações nas cooperativas também se manifesta, pela lógica da manutenção do poder, do status quo, do medo e insegurança quanto ao novo.

Para Pies (2017) a mudança institucional torna-se efetiva na medida em que os atores inseridos no contexto têm a capacidade de promover a tradução de novas formas institucionais para a realidade, estabelecendo, difundindo e consolidando novas regras, promovendo inovações e modificando os arranjos institucionais existentes, a partir da introdução de novas práticas e de novos sentidos para a cooperativa.

No manual de boas práticas de governança do BACEN (2015), aparece com clareza a necessidade de separação dos papéis desempenhados pelo Conselho de Administração e diretoria Executiva. Segundo o IBGC (2015), considerando que o papel do conselho "é o monitoramento da diretoria executiva no alcance da estratégia, não é recomendável que o conselheiro ocupe qualquer cargo na diretoria executiva, uma vez que limitaria sua atuação neste monitoramento". Na visão de Meinen e Port (2014), cabe à diretoria executiva atuar no plano tático, transformar em práticas as orientações do conselho, conduzir a gestão e prestar contas para as instâncias superiores. 


\section{PROPOSIÇÕES DO ESTUDO}

Através da pesquisa, contemplando a coleta de dados, sistematização, análise e interpretação dos dados, com a sua descrição, oportuniza-se este ambiente para as proposições do estudo. Com relação a estrutura de gestão e governança, que é o objeto central deste estudo, e as deliberações tomadas pelas instâncias superiores da cooperativa, aprovadas pelo Banco Central e descritas na seção anterior, é detalhada a proposta de uma estrutura organizacional abrangendo a estrutura de governança cooperativa e a gestão executiva.

A proposição deste modelo de estrutura de governança corporativa da Cresol Santo Cristo em por finalidade contribuir com a qualificação da estrutura cooperativa, a transparência, a sustentabilidade e longevidade, e o aprimoramento da performance do negócio e dos serviços prestados. NO seu conjunto, referenciado pelo seu planejamento estratégico e aprimoramento contínuo das suas práticas de gestão e governança. O Modelo proposto é ilustrado na Figura 01. 
Figura 1 - Nova estrutura de governança corporativa da Cresol Santo Cristo

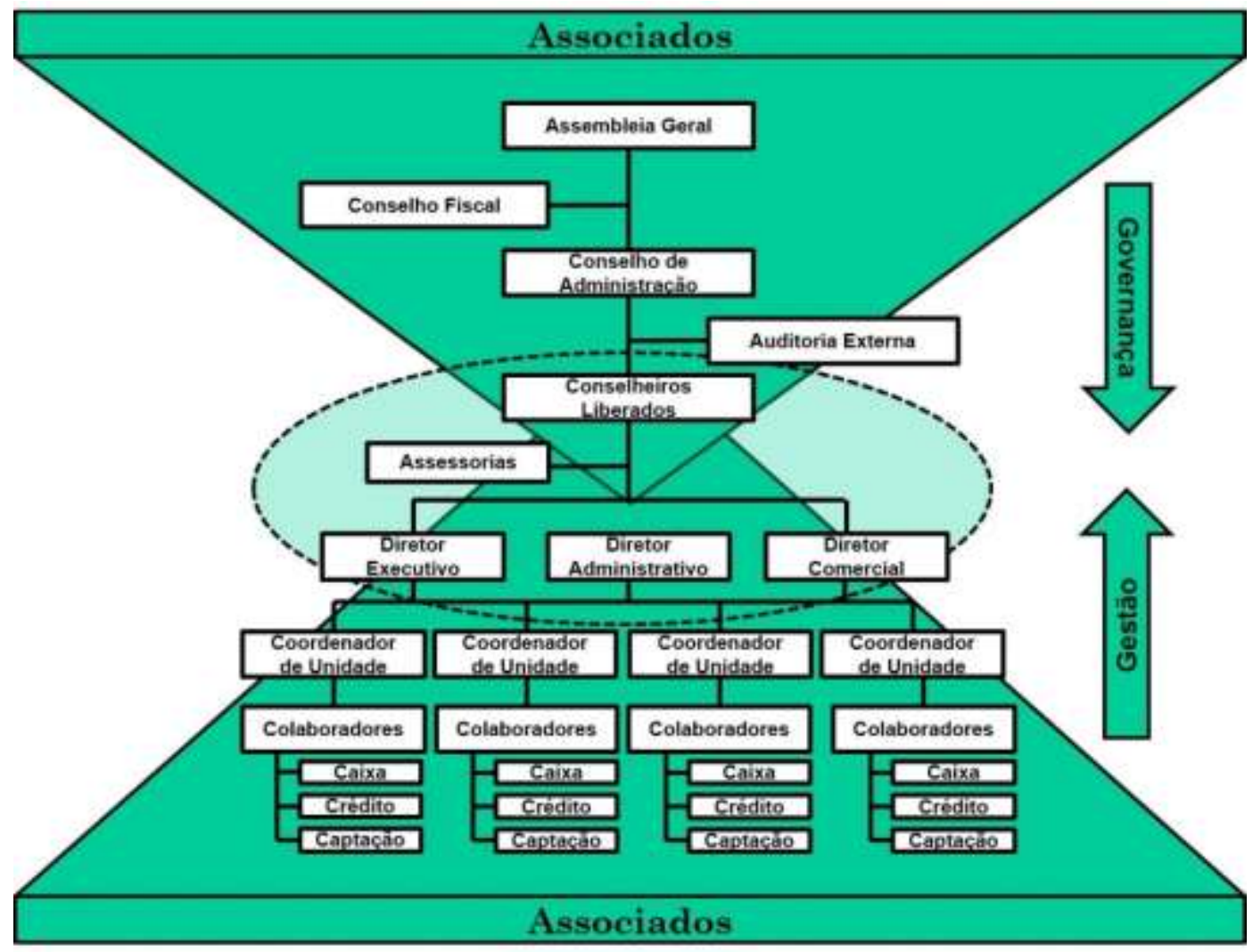

Fonte - Elaboração dos autores.

A estrutura organizacional proposta apresenta os diversos níveis hierárquicos, abrangendo dimensão associativa e a dimensão executiva contratada. A Assembleia geral de associados é o órgão máximo de poder e deliberação na cooperativa. Subordinados à Assembleia Geral, estão o Conselho de Administração e o Conselho Fiscal, ambos compostos por membros associados, eleitos em assembleia, com mandatos próprios e atribuições definidas em lei e estatutos sociais. Em subordinação encontram-se Conselheiros liberados, membros do Conselho Administração. Estes constituem o nível hierárquico mais alto da presença contínua dos associados na gestão da cooperativa.

O nível hierárquico seguinte é composto pelos diretores executivos contratados, com competências profissionais específicas para a gestão de suas respectivas áreas e atribuições. Estas definidas em Estatuto e demais normatizações 
da legislação atinente as cooperativas de crédito. Os diretores executivos, compreendendo a Diretorias Executiva, a Diretoria Administrativa e a Diretoria Comercial, são subordinadas ao Conselho de Administração, representado pela presença contínua dos Conselheiros Liberados. Em continuidade, detalha-se a estrutura de organização e funcionamento das áreas e as respectivas unidades de atendimento e seus principais cargos alocados.

$\mathrm{Na}$ estrutura reconhece-se a combinação articulada do corpo associativo cooperativo, representado pela governança associativa, com o corpo diretivo executivo e funcional, representado pela configuração da gestão. Na dimensão primeira, está à organização societária, composta pelos associados e seus representantes eleitos, e a dimensão da gestão, composta pela estrutura funcional, a quem cabe operacionalizar e viabilizar o negócio cooperativo.

A confluência dos dois elementos triangulares, constitui-se no ambiente de combinação de interesses resultantes da base, objetivos e finalidades cooperativos e a referência executivo-profissional de performance do negócio. Esta definição corrobora com as definições do IBGC (2009), Büttenbender (2010, 2011 e 2017) e BACEN (2015 e 2019). Este ambiente, que em sua operacionalidade contínua demonstra que na governança corporativa, se delimita como o 'conflito de agência'. Esclarecendo que 'conflito de agência', de acordo com Büttenbender (2017), é a combinação de interesses associativo-cooperativo, expressos pelos interesses dos sócios, através das instâncias superiores, e o conjunto das demandas e peculiaridades operacionais de negócio e do mercado, expressos pelos membros associados na sua condição de clientes operacionais dos negócios cooperativos.

Conforme prevê o próprio estatuto, a Diretoria Executiva conta com uma preocupação mais voltada ao recurso humano da cooperativa. Busca-se assim a identificação dos perfis e potencialidades bem como as dificuldades de cada um, apontando alternativas para melhorar a produção de cada colaborador e 
consequentemente a melhorar dos resultados de cada unidade. Somam-se a isso as das principais carências de cada unidade e apontar ações estratégicas para suprir as deficiências. Conversas sobre situações pontuais com colegas, com intuito de promover ações direcionadas aos percalços e maiores dificuldades de cada unidade e o incentivo e motivação aos colegas ao trabalho com reuniões motivadoras em prol de resultados para a cooperativa, bem como a realização profissional e a satisfação pessoal de todos fazem-se meios de construção dos fins buscados.

Além destas funções a Diretoria Executiva convoca reuniões, elabora as atas da diretoria Executiva e Conselho Administrativo. Participa das reuniões do Conselho Administração, onde define o planejamento, os indicadores de desempenho, presta informações do desempenho de cada uma das atividades da cooperativa e coordena a avaliação.

A Diretoria Comercial por sua vez desempenha a função de estudar e socializar os novos produtos e serviços que vão sendo implantados na cooperativa. No lançamento e implantação, muitas são as dúvidas do colaborador em relação a funcionalidade e benefícios ao cooperado destes produtos e serviços que vão despontado e sendo criados. Além disto, o diretor comercial elabora campanhas de vendas de credito, intermedia negociações diretamente com alguns cooperados de potencial, visando alavancar indicadores financeiros da Cresol, auxiliando também no acompanhamento das unidades de atendimento, sugerindo ações a serem incrementadas.

A Diretoria Administrativa tem por função principal na recuperação de crédito, minimizando as perdas da cooperativa. A alta inadimplência pode comprometer o resultado da cooperativa. Com a intervenção direta da diretora administrativa para intermediar as negociações mais complicadas evitando desta forma a cobrança judicial, o que acarreta em despesas diretas para o cooperado e a cooperativa. Além das atividades citadas, outras inúmeras funções fazem parte do dia da Diretoria 
Administrativa. A assinatura em documentos oficiais da cooperativa, representação da cooperativa perante juizado, Ministério do Trabalho entre outros.

Com a implantação da diretoria executiva, busca-se uma adoção da boa prática de Governança na cooperativa que garante a aplicação da autogestão no Sistema Cooperativista Nacional e tem por finalidades ampliar a transparência da administração da sociedade cooperativa; Facilitar o desenvolvimento e a competitividade das cooperativas; Contribuir para a sustentabilidade e perenidade do modelo cooperativista; Praticar a autogestão como forma de aprimorar a participação do cooperado no processo decisório; Obter melhores resultados econômicofinanceiros; Incentivar a inovação e proporcionar a melhoria da qualidade dos serviços ao quadro social e aplicar a responsabilidade social como integração da cooperativa com a sociedade civil.

Propõem-se a capacitação dos conselheiros com funções não executivas, possibilitando assim um equilíbrio do conhecimento das funções, atribuições e as responsabilidades do conselheiro, bem como da cooperativa de forma geral, a fim de que os princípios e o interesse da cooperativa sempre prevaleçam.

Outro desafio contínuo da diretoria executiva é conquistar e manter saudável nível de confiança do Conselho Administrativo, viabilizando a qualificada gestão e desenvolvimento da cooperativa, conforme os Estatutos, definições das Assembleias Gerais, o planejamento estratégico e os objetivos estabelecidos pela Cooperativa.

\section{CONSIDERAÇÕES FINAIS}

A partir do desenvolvimento do estudo é possível indicar e reconhecer a amplitude e importâncias das organizações cooperativas, seu princípios, fundamentos legais e peculiaridades, expressos pelos sistemas organizacionais e complexidade da governança e gestão. 
A importância e oportunidade da realização de estudos desta natureza, momento que as cooperativas, especialmente as de crédito, vivem intenso processos de reformulação de estruturas de governança e de gestão, visando atender a expansão e crescente participação no mercado, os avanços e inovações nas estruturas e gestão dos negócios financeiros e as exigências legais e de regulamentação das operações e o funcionamento. O necessário e vigoroso investimento na qualificação e capacitação de suas lideranças e gestores, no ambiente de abertura de mercados, maior competitividade e necessidade de geração de resultados para os seus membros e a sociedade.

Considera-se que o objetivo desta pesquisa foi atingido, destacando que foi o de diagnosticar as vantagens, desafios e aprimoramentos decorrentes da implantação da estrutura de governança corporativa na Cresol Santo Cristo. Desta forma, visando assim a qualificação da gestão e garantindo maior segurança, transparência e alcance dos resultados pretendidos pela cooperativa.

Sem esgotar o tema, resta apontar que os resultados desta pesquisa passam a gerar contribuições importantes, na sistematização de conhecimentos e nos aportes à contínua qualificação da estrutura de governança e gestão de cooperativa Cresol Santo Cristo e de todo o cooperativismo. O aprimoramento contínuo, as inovações e mudanças provocadas pelo ambiente e as próprias cooperativas, indicam para uma estrutura viva e em contínuo aperfeiçoamento, adequando-a as necessidades da realidade desta cooperativa. Igualmente poderá resultar em referência para outras cooperativas do Sistema Cresol e de outros sistemas cooperativos, de modo a orientarem os seus processos de implantação de estruturas de governança e gestão cooperativa.

Novas questões e inquietudes de pesquisa resultam deste estudo, destacando temas tais quais: como se comportará o desenvolvimento cooperativo a partir da consolidação desta nova estrutura de governança e gestão? Quais as repercussões 
decorrentes das alterações nas estruturas e configurações de poder e de liderança na cooperativa? Quais aportes estes novos modelos de governança e gestão produzirão na qualificação da performance das cooperativas, seja do Sistema Cresol, das demais Cooperativas de Crédito e dos demais segmentos? Quais novas competências de governança e gestão serão requeridas aos diretores contratados, diretores eleitos, conselheiros, associados e colaboradores da cooperativa? Quais as repercussões na imagem e desempenho das cooperativas frente aos demais stakeholders do cooperativismo e os demais agentes econômicos, sociais e políticos?

O estudo, ao finalizar, reconhece e valoriza estudos anteriores, direcionados ao cooperativismo, a governança corporativa e a gestão. Converge com definições de governança corporativa em diferentes tipologias organizacionais. No entanto, agrega os fundamentos peculiares as cooperativas e cooperativas de crédito, que se constituem em uma tipologia organizacional própria e que são orientadas pelos princípios e fundamentos legais que Ihe são próprios. Por isto que as cooperativas geram importantes aportes ao desenvolvimento econômico e social aos seus membros e para a sociedade nas quais estão inseridos. O seu fortalecimento e a qualificação continua de suas estrutura e modelos de gestão, em muito poderão contribuir com o fortalecimento das cooperativas e o cumprimento destes objetivos e finalidades maiores.

\section{REFERÊNCIAS}

ANDRADE, A.; ROSSETTI, J. P. Governança Corporativa: fundamentos, desenvolvimento e tendências. 3. ed. São Paulo: Editora Atlas, 2007.

BACEN. Resolução n. 4434 de 05 de agosto de 2015. Disponível em: https://www.bcb.gov.br/pre/normativos/busca/downloadNormativo.asp?arquivo=/List s/Normativos/Attachments/48507/Res_4434_v1_O.pdf. Acesso em: 13 jun. 
2018.BRASIL. Lei complementar $\mathrm{n}^{\circ}$ 130, de 17 de abril de 2009. Dispõe sobre o Sistema Nacional de Crédito Cooperativo e revoga dispositivos das Leis nos 4.595, de 31 de dezembro de 1964, e 5.764, de 16 de dezembro de 1971. http://www.planalto.gov.br/ccivil_03/leis/lcp/Lcp130.htm. Acessado em 03.02.2019.

BRASIL. Lei $\mathrm{n}^{\circ}$ 5.764, de 16 de dezembro de 1971. Define a Política Nacional de Cooperativismo, institui o regime jurídico das sociedades cooperativas, e dá outras providências. http://www.planalto.gov.br/ccivil_03/LEIS/L5764.htm. Acessado em 09.09.2018

BÜTTENBENDER, P. L. Governança In: Dicionário de Desenvolvimento Regional e Temas Correlatos. Porto Alegre RS: Ed. Conceito, 2017.

BÜTENBENDER, P. L. Cooperativismo na Região Noroeste do Rio Grande do Sul Experiências de gestão cooperativa e de promoção do desenvolvimento. Ed. Sescoop/RS. Porto Alegre, 2010.

BÜTTENBENDER, P. L. Gestão de Cooperativas. Fundamentos, Estudos e Práticas. Ijuí/RS. Ed. Unijuí, 2011.

BÜTTENBENDER, P. L.; MAGRI, C. A. Fundamentos do Cooperativismo: Evolução, Histórico e Perspectivas. Francisco Beltrão, PR: Grafisul, 2018.

BÜTTENBENDER, P. L.; NICKEL, K. et al. Estruturas de governança corporativa em cooperativas e repercussões no âmbito territorial: o caso de uma cooperativa de crédito. In: Anais VIII SIDR, 2017, Santa Cruz do Sul. UNISC, 2017.

BÜTTENBENDER, P. L.; NICKEL, K.; HASS, F. R. Estudo sobre a estrutura de governança de uma cooperativa de crédito: o caso da Sicredi União RS In: Anais do III CONLAD Congreso Latinoamericano de Administración. Posadas, MI, AR: Ed. UNAM, 2016. 
COLLIS, J., HUSSEY, R. Pesquisa em administração: um guia prático para alunos de graduação e pós-graduação. 2.ed. Porto Alegre: Bookman, 2005.

CRESOL SANTO CRISTO. Cresol Santo Cristo. Disponível em: https://cresolsicoper.com.br/santo-cristo/quem-somos. Acesso em: 09 de maio 2018.

GIL, A. C. Como elaborar projetos de pesquisa. 4.ed. São Paulo: Atlas, 2002.

IBGC. A Prática da Sustentabilidade: Desafios vividos por agentes da Governança Corporativa. Instituto Brasileiro de Governança Corporativa. São Paulo, SP: IBGC, 2009.

MAGRI, C. A. (org.) Cooperativismo de Crédito Solidário: reflexões e boas práticas. Passo Fundo: IFIBE, 2010. 325pg.

MAGRI, C. A., POMMERENING, E. J. (org.) O Cooperativismo financeiro e a agricultura familiar: gerando desenvolvimento sustentável. Joaçaba: Editora Unoesc, 2018. 152pg.

MEINEN, Ê. Governança nas Cooperativas de Crédito. Disponível em: http://cooperativismodecredito.coop.br/2010/10/ainda-sobre-governanca-nascooperativas-de-credito/. Acesso em: 29 abr. 2018.

MEINEN, Ê.; PORT, M. Cooperativismo Financeiro: Percurso Histórico, Perspectivas e Desafios. Brasília: Confebras, 2014.

MOTTA, P. R. Gestão contemporânea: a ciência e a arte de ser dirigente. $4^{\mathrm{a}}$ ed. Rio de Janeiro: Record, 1994. 256 pg.

OLIVEIRA, D. de P. R. de. Manual de Gestão de Cooperativas: uma abordagem prática. 2ed. São Paulo: Atlas, 2003. 318 pg. 
PIES, M. P. Institucionalização e mudanças nas práticas organizacionais: um estudo dos mecanismos de governança no cooperativismo de crédito solidário / Marcelino Pedrinho Pies - São Caetano do Sul: USCS - Universidade Municipal de São Caetano do Sul, 2017.

SCHARDONG, A. Cooperativa de Crédito: instrumento de organização econômica da sociedade. Porto Alegre: Rigel, 2003.

SIQUEIRA, L. C.; BIALOSKORSKI, S. Práticas de governança corporativa indicadas para monitoramento: uma análise do nível de adoção em cooperativas agropecuárias. REGE. São Paulo - SP, Brasil, v. 21, n. 1, p. 43-63, jan./mar. 2014.

SOARES, M.; MELO SOBRILHO, A. Microfinanças: o papel do Banco Central do Brasil e a Importância do Cooperativismo de Crédito. Brasília: Banco Central do Brasil, 2008.

VENTURA, E. C. F. (Coord.). Governança cooperativa: diretrizes e mecanismos para o fortalecimento da governança em cooperativas de crédito. Brasília: BCB, 2009. 256 p.

YIN, R. K. Estudo de caso: planejamento e métodos. 4. ed. Porto Alegre: Bookman, 2010.

ZAMBERLAN, L. (Org.) [et al.]. Pesquisa em Ciências Sociais Aplicadas. Ijuí: Ed. Unijuí, 2014. 
